\title{
Made for Eating! ${ }^{1}$
}

\author{
Charles Jacoby, Nanette Holland, and Debbi Berger ${ }^{2}$
}

\section{UF | FLORIDI IFAS Extension}

The Institute of Food and Agricultural Sciences (IFAS) is an Equal

Opportunity Institution authorized to provide research, educational information and other services only to individuals and institutions that function with nondiscrimination with respect to race, creed, color, religion, age, disability, sex, sexual orientation, marital status, national origin, political opinions or affiliations. For more information on obtaining other extension publications, contact your county Cooperative Extension service.

U.S. Department of Agriculture, Cooperative Extension Service, University of Florida, IFAS, Florida A. \& M. University Cooperative Extension Program, and Boards of County Commissioners Cooperating. Larry Arrington, Dean.

\section{Copyright Information}

This document is copyrighted by the University of Florida, Institute of Food and Agricultural Sciences (UF/IFAS) for the people of the State of Florida. UF/IFAS retains all rights under all conventions, but permits free reproduction by all agents and offices of the Cooperative Extension Service and the people of the State of Florida. Permission is granted to others to use these materials in part or in full for educational purposes, provided that full credit is given to the UF/IFAS, citing the publication, its source, and date of publication.

\footnotetext{
${ }^{1}$ This document is CIR1508, an Activity in an Invasive Species Curriculum (CIR1496), and it is reprinted by permission of the Tampa Bay Estuary Program and The Florida Aquarium. Original EDIS publication date: January, 2007. It was supported by the Tampa Bay Estuary Program, the Florida Aquarium, the Department of Fisheries and Aquatic Sciences of the University of Florida, and the National Sea Grant College Program of the National Oceanic and Atmospheric Administration (NOAA), U.S. Department of Commerce, under NOAA Grant No. NA 16RG-2195. Visit the EDIS Web Site at http://edis.ifas.ufl.edu.

${ }^{2}$ Charles Jacoby, Assistant Professor, Department of Fisheries and Aquatic Sciences, Cooperative Extension Service, Institute of Food and Agricultural Sciences, University of Florida, Gainesville, 32611; Nanette Holland, Public Outreach Coordinator, Tampa Bay Estuary Program, 100 8th Avenue S.E., MS I-1 / NEP, St. Petersburg, FL 33701; Debbi Berger, Vice President of Education, The Florida Aquarium, Inc., 701 Channelside Drive, Tampa, Florida, 33602.
} 
This page was intentionally left blank. 


\section{Invasive Species \\ Series
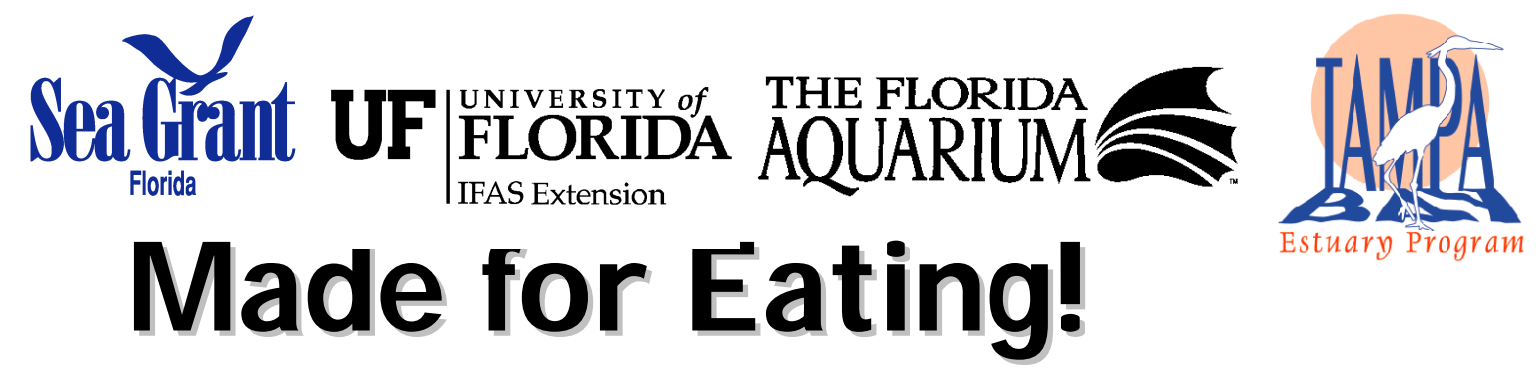

Sne ak Peek

Students will study the parts of

a fish to develop the

understanding that the shape,

form and structure of a fish's

parts influence its lifestyle and

behavior. The Flathe ad Catfish

is a Florida invader, which is

extremely successful in part

due to its voracious appetite.

$S$ tudents will identity the

morphology of this fish and find

out how this helps its success.

This activity incorporates data

analys is, writing skills, graphic

arts, and critic al thinking.

Aligned with the following

$S$ unshine State Standards and

FCAT Benchmarks for grades

$6 \cdot 8:$

SC.D.2.3.2 $\mathcal{A} \mathcal{A} \quad$ SC.G.2.3.4 AA

SC.F.1.3.7 CS SC.H.2.2.1 CS

SC.G.2.3.3 CS

$\mathcal{A} \mathcal{A}=$ annually assessed

CS = content sampled

\section{Objectives:}

Students will:

- Identify the various parts of a fish.

- Investigate the concept of fish morphology.

- Relate shape, form and structure of a fish's parts to their functions.

- Draw inferences about where and how a fish might live based on its morphology.

- Understand why the morphology of the Flathead Catfish, Pylodictis olivaris, makes it such a successful predator.

\section{Materials:}

- Rubber fish models (can be purchased from N ASC 0 1-800-558-9595) or several different kinds of whole frozen fish that demonstrate different shapes (flounder, skate or ray, an eel, a perch, sea bass, angel fish, tuna or mackerel) obtained from your local fish market, supermarket or from a nearby marine research facility. 0 nce obtained, fish can be frozen and reused at your discretion.

- Tempera paint.

- Paint brushes.

- Colored markers.

- N ewsprint paper, or other kind of craft paper.

- Newspaper.

- Fish anatomy diagram and fish morphology chart (included).

- Q uestions W orksheet.

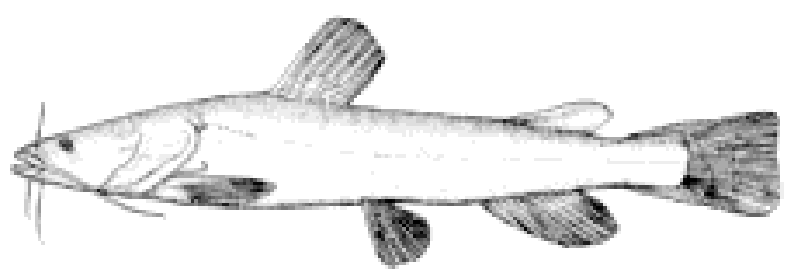

Flathead catfish illustration from $\mathrm{C}$ anadian Museum of $\mathrm{N}$ ature 


\section{Background:}

Invasive species are plants or animals that are not native to a particular area and cause ecological or economic harm. A nimal invaders can out-compete native species by avoiding predators better or finding or capturing prey better. The bodies of animals provide clues about their competitive abilities, and fish provide several excellent examples.

Fish shape and anatomy helps us discover information about how a fish moves, where and how the fish lives, and how it has adapted to its environment. Morphology is the study of the structure and form of living things. Body shape, mouth location and size, tail shape and body color give us clues as to how animals live.

Body shape is a good indicator of how a fish moves and where it lives. Fish that are flat or depressiform, like a skate, flap their fins up and down to swim through the water in the same way a bird flaps its wings.

Flounder normally live on the bottom of the sea floor. Meanwhile, fish that are long and skinny, or filiform, like an eel, slither through the water like a snake. Fish that are streamlined and have an oval or fusiform cross-section, like a tuna or striped bass, are fast swimmers and usually live in open water. A compressiform shape like that of angelfish looks thin when viewed from the front. This body shape is well designed for making quick turns and quick bursts of speed over short distances. Compressiform fish commonly live where there are many places to hide such as among plants in lakes or on coral reefs.

The shape of a fish's tail also indicates how the fish moves and lives.

Rounded, truncated or emarginate tails, like that of a killifish or minnow, are increasingly better for maneuverability and short bursts of speed with less drag. A forked tail, like that of a striped bass, is good for maneuverability and speed over longer distances. Lunate, or crescent shaped tails, like those found on a swordfish are not good for maneuvering but allow for great speed over long distances and are usually found on fish that live in the open ocean.

The size and location of the mouth tells us a lot about where a fish finds its food, what food it eats, and where it may live. Fish with a large mouth generally eat large pieces of food. Fish with a small mouth generally eat small items of food, such as plankton. If the mouth is oriented upwards, it is a surface feeder (or it feeds on prey above it) like a stargazer or stonefish. If the mouth is located in the middle front of the head, like a tuna, 
we can assume that the fish feeds on prey directly in front of it. If the mouth is oriented downwards, it is a bottom feeder, like the catfish. Some fish have elongated tube-like mouths to reach into crevices. An example of this type is a butterfly fish. 


\section{Procedure:}

1. Review fish anatomy and explain that all fish have the same basic body parts. However, those parts may look different. Have students hypothesize why different body parts are shaped differently. Introduce the concept of fish morphology or how the form and shape of a fish and its parts influence function.

2. Students will spend approximately $10-30$ minutes doing G yotaku (Jee-oh-tăk-00), the ancient Japanese art of fish printing using rubber models or real fish. If real fish are used, wash, blot dry and, if frozen, thaw slightly before printing. Lay fish flat on top of newspaper. Brush a thin layer of paint on the exposed side of the fish.

3. The best prints result from the least amount of paint while still attaining full coverage. C arefully lay a sheet of paper on top of the painted fish, and gently press paper down onto all parts of the fish to help pick up details. Slowly lift the paper to reveal the print and place aside to dry. 0 ften a fresh coat of paint is not necessary before the next print.

4. Have students label the external anatomy of the fish and use the fish morphology charts to label the body shape of their fish and the fish's tail on their prints.

5. Have students compare and contrast the morphology of their fish and those in the prints that were made from other species of fish. Have students write a paragraph about their fish's possible behavior and habitat based on its shape and anatomy.

6. Have students review pictures of the Flathead $\mathrm{C}$ atfish. Have students describe the body shape and tail shape. Lead a discussion on why these voracious eaters are so successful in large part due to their morphology. Instruct students to draw a picture of the Flathead C atfish on scrap paper.

7. Lead a discussion about how the morphology of other invasive species in Florida might contribute to their success. 
Body Shape

\begin{tabular}{|l|l|l|l|}
\hline Cross section & \multicolumn{1}{|c|}{ Shape } & Locomotion \\
\hline & Fusiform & $\begin{array}{l}\text { Fast-swimming in } \\
\text { open water }\end{array}$ \\
\hline & Compressiform & $\begin{array}{l}\text { Capable of quick } \\
\text { bursts of speed } \\
\text { over short } \\
\text { distances }\end{array}$ \\
\hline Skate/Ray & $\begin{array}{l}\text { Swimming often } \\
\text { resembles a } \\
\text { bird's wings in } \\
\text { motion }\end{array}$ \\
\hline & Depressiform & $\begin{array}{l}\text { Undulates } \\
\text { though the water } \\
\text { in a snake-like } \\
\text { manner }\end{array}$ \\
\hline
\end{tabular}

Caudal Fin (Tail) Shape

\begin{tabular}{|l|l|}
\hline Shape & Function \\
\hline Rounded & $\begin{array}{l}\text { Large surface area for acceleration } \\
\text { and maneuvering, but creates drag } \\
\text { that causes fatigue }\end{array}$ \\
\hline Less drag than rounded tail, effective \\
acceleration and maneuvering
\end{tabular}




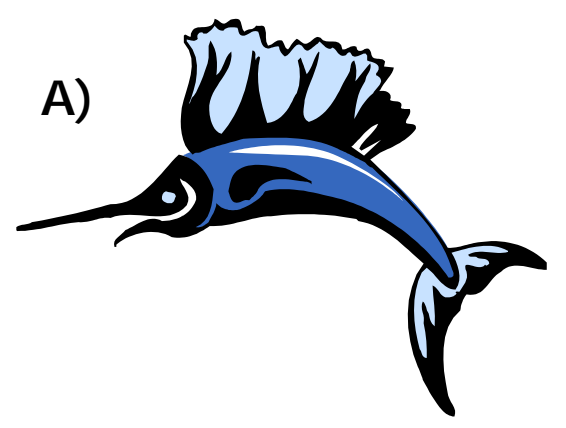

B)



C)

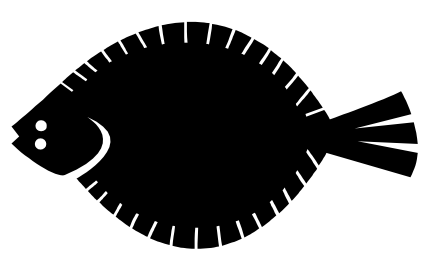

D)

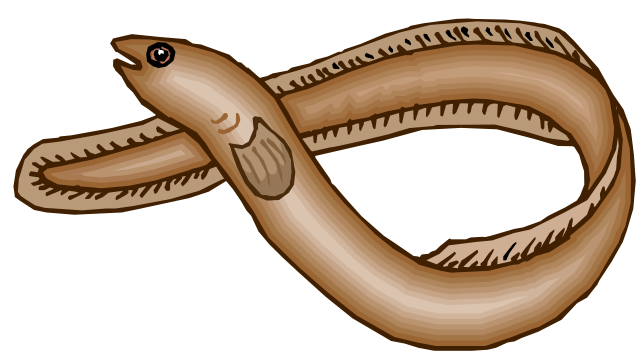

\section{Using the information on the previous page, answer the following questions:}

1. W hich of the fish above swims the fastest in open water?

2. W hich fish can make sharp turns?

3. W hich fish is a great sprinter but not fit for a long distance marathon?

4. W hich fish swims like a flying bird?

5. W hich fish slithers through the water like a snake?

6. W hich fish lives on the sea floor? 


\section{Glossary:}

Anatomy - The study of the parts of an organism in order to ascertain their position, relationship, structure and function.

Compressiform - Body flat from side to side and tall and thin when viewed from the front.

Depressiform - Body flattened from top to bottom and wide and thin when viewed from the front.

Emarginate - Having a notched margin.

Filiform - Long, skinny tube-shaped body.

Forked - H aving two or more branches or points.

Fusiform - Streamlined oval-shaped body.

Lunate - shaped like a crescent or quarter-moon.

Morphology - The study of organisms' structure or form.

Plankton - Small plants or animals that cannot swim strongly, so they drift with currents.

Rounded - C urved or shaped like part of a circle.

Truncate - Short and square or slightly rounded. 